\title{
Methotrexate hepatotoxicity in psoriatics: Report of 104 patients from Nova Scotia, with analysis of risks from obesity, diabetes and alcohol consumption during long term follow-up
}

DA Malatjalian mD, JB Ross mD, CN Williams mD, SJ COlWell mD, BJ EAstwoOd PhD

DA Malatjalian, JB Ross, CN Williams, SJ Colwell, BJ EASTWOOD. Methotrexate hepatotoxicity in psoriatics: Report of 104 patients from Nova Scotia, with analysis of risks from obesity, diabetes and alcohol consumption during long term follow-up. Can J Gastroenterol 1996;10(6):369-375.

BACKGROUND AND DESIGN: Methotrexate (MTX) hepatotoxicity in psoriatic patients is well recognized, but there are discrepancies in the reported incidence and associated risk factors. This retrospective study describes 104 Nova Scotian patients with psoriasis seen between 1979 and 1990. Patients received MTX over one to 11 years (mean 3.38), with baseline and annual follow-up liver biopsies. Clinical data were obtained by chart review. Statistical analysis evaluated the risks associated with obesity, diabetes, alcohol consumption and duration of therapy, with the histological grade of liver biopsies.

RESULTS: Of the 104 patients, 35 were obese, 10 were diabetic and 37 occasionally consumed alcohol. At the end of the study, 21 patients had developed severe hepatic fibrosis (grade IIIB), and three developed liver cirrhosis (grade IV). Significant risk of severe hepatotoxicity is related to diabetes $(\mathrm{P}=0.02)$ but not to obesity
$(\mathrm{P}=0.12)$ or alcohol consumption $(\mathrm{P}=0.12)$. All patients with cirrhosis took MTX for two years in standard doses of 20 to $25 \mathrm{mg} /$ week.

CONCLUSIONS: In this first Canadian study evaluating MTX hepatotoxicity in psoriatics, the incidence of severe hepatotoxicity is high: $23.1 \%$ (24 of 104 patients). This study shows that diabetic patients are particularly at increased risk of MTX hepatotoxicity. Occasional alcohol consumption is not associated with increased risk. Three patients who developed cirrhosis over two years of standard MTX therapy may represent a subset of psoriatics with increased hepatic susceptibility to MTX. Another three patients whose severe hepatic fibrosis had regressed upon discontinuation of MTX, but who developed accelerated recurrence of the severe hepatic fibrosis upon resumption of MTX therapy, also suggest the possibility of unusual sensitivity to the drug. These cases emphasize the need for continuing surveillance, with regular liver biopsies, of psoriatic patients on MTX. (Pour le résumé, voir page 370)

Key Words: Alcohol consumption, Diabetes, Hepatotoxicity, Liver biopsy, Methotrexate, Psoriatics

Presented in part at the 18th World Congress of Dermatology held in New York, June 12 to 18, 1992

Divisions of Anatomical Pathology, Dermatology, Gastroenterology, Department of Community Health and Epidemiology, Dalhousie University and Victoria General Hospital, Halifax, Nova Scotia

Correspondence and reprints: Dr DA Malatjalian, Division of Anatomical Pathology, Victoria General Hospital, Halifax, Nova Scotia

B3H 2Y9. Telephone 902-428-3892, fax 902-428-3978, e-mail dickran@is.dal.ca

Received for publication May 10, 1995. Accepted January 3, 1996 


\section{Réaction d'hépatotoxicité au méthotrexate chez des sujets atteints de psoriasis : rapport sur 104 patients néo-écossais avec analyse des risques liés à l'obésité, au diabète, à la consommation d'alcool au cours d'un suivi à long terme}

DONNÉES DE DÉPART ET MODÈLE : L'hépatotoxicité au méthotrexate (MTX) chez les patients atteints de psoriasis est bien connue, mais certaines discordances ont été notées quant à l'incidence et aux facteurs de risque qui y sont associés. Cette étude rétrospective dresse un bilan de 104 patients néo-écossais atteints de psoriasis, vus entre 1979 et 1990. Les patients ont eu du MTX sur une période allant de 1 à 11 ans (moyenne 3,38) et ont subi des biopsies hépatiques au départ et lors de suivis annuels. Les données cliniques ont été obtenues à partir des dossiers. L'analyse statistique a évalué les risques associés à l'obésité, au diabète, à la consommation d'alcool et à la durée du traitement avec le degré histologique des biopsies hépatiques.

RÉSULTATS : Parmi les 104 patients, 35 étaient obèses, 10 étaient diabétiques et 37 consommaient de l'alcool à l'occasion. À la fin de l'étude, 21 patients avaient développé une grave fibrose hépatique (stade IIIB) et trois présentaient une cirrhose hépatique (stade IV). Un risque important d'hépatotoxicité grave est lié au diabète $(P=0,02)$, mais non à l'obésité $(P=0,12)$ ou à la consommation d'alcool $(P=0,12)$. Tous les patients atteints de cirrhose avaient pris du MTX pendant deux ans aux doses normales de 20 à $25 \mathrm{mg} /$ semaine.

CONCLUSIONS : Dans le cadre de cette première étude canadienne sur l'hépatotoxicité liée au MTX chez les patients atteints de psoriasis, l'incidence d'hépatotoxicité grave est élevée : 23,1\% (24 patients sur 104). Cette étude révèle que les patients diabétiques sont exposés à un risque particulier à l'égard d'une réaction d'hépatotoxicité au MTX. La consommation occasionnelle d'alcool n'est associée à aucun accroissement de risque. Trois patients chez qui la cirrhose s'est installée sur une période de deux ans de traitement au MTX aux doses normales pourraient représenter une sous-catégorie de patients atteints de psoriasis présentant une fragilité hépatique accrue associée au MTX. Trois autres patients dont la fibrose hépatique grave avait régressé à l'arrêt du traitement par MTX et qui ont développé une récurrence accélérée de fibrose hépatique grave à la reprise du traitement par MTX permettent de supposer la possibilité d'une sensibilité spéciale au médicament. Ces six patients rappellent la nécessité de surveiller attentivement au moyen de biopsies hépatiques régulières les patients atteints de psoriasis traités au MTX.
$\mathrm{M}$ ethotrexate (MTX) is widely used in the treatment of severe forms of psoriasis and psoriatic arthritis. A number of studies have documented its efficacy and the high degree of patient compliance (1-5).

The many complications that are associated with MTX have been significantly reduced by using low and intermittent doses. However, the potential for hepatic fibrosis and cirrhosis remains a major concern with long term treatment. The data from the literature reveal an incidence of hepatic cirrhosis varying from $0 \%(6,7)$ to $25.6 \%(8)$.

Guidelines formulated by Roenigk and co-workers (9) in 1972, and later revisions in 1973 (10), 1982 (11) and 1988 (12) offer recommendations on the indications for and the dosage of MTX, and on initial and follow-up assessments of psoriatic patients. In addition to the clinical and laboratory assessments of renal, hematopoietic and hepatic functions, the guidelines recommend histological evaluation of a preMTX liver biopsy and repeat annual biopsies while the patient is on the drug or after every 1 to $1.5 \mathrm{~g}$ cumulative MTX intake.

While the duration of treatment and the cumulative dose seem to have an important role in the evolution of MTXinduced hepatotoxicity, a number of other risk factors have been identified. These include alcohol, obesity, diabetes mellitus, increased age and pre-existing liver disease $(6,8$, 13,14).

Several studies have attempted to clarify the relation between MTX-induced hepatic fibrosis and cirrhosis, and other risk factors such as age, diabetes, obesity, alcohol ingestion, duration of treatment or cumulative dose (1416), with some conflicting results. We report our experience with 104 psoriatic patients who received MTX weekly and underwent annual liver biopsies for histological monitoring.

\section{METHODOLOGY}

Histology: All liver biopsies between 1979 and 1990 from psoriatic patients on MTX therapy were retrieved from the files of the Division of Anatomical Pathology at the Victoria General Hospital, Halifax, Nova Scotia. The biopsies had been serially cut to be $5 \mu \mathrm{m}$ thick and all had a minimum of three hematoxylin and eosin stained sections, one Masson's trichrome stained section for connective tissue and one section stained for iron using Perls' reaction. When appropriate, one or more of the following additional stains were done: periodic acid Schiff with or without pretreatment with diastase, Shikata orcein stain for hepatitis B virus surface antigen and van Gieson stain for connective tissue. The slides were reviewed unblinded by an author and the following histological variables were tabulated: degree of steatosis; amount and cellular distribution of stainable iron; presence of centrilobular sinusoidal fibrosis; amount of portal inflammation; extent of portal fibrosis; presence of periportal inflammation; presence of periportal fibrosis; presence of bridging fibrosis; degree of hepatocellular nuclear variability; presence and extent of hepatocellular degeneration; presence and extent of hepatocellular necrosis; presence and extent of lobular inflammation; and presence of cirrhosis.

Steatosis was graded 0 when absent, +1 (mild) when centrilobular, +2 (moderate) when centrilobular and midzonal, and +3 (severe) when panlobular in distribution. The stainable iron, the inflammation in portal, periportal and lobular areas, and both hepatocellular degeneration and necrosis were graded as absent $(0)$, or empirically as mild $(+1)$, moderate $(+2)$ or severe $(+3)$.

Periportal fibrosis, bridging fibrosis and cirrhosis were graded as absent (0) or present (1). Cirrhosis was diagnosed only in the presence of regenerative nodules surrounded by fibrous tissue. 


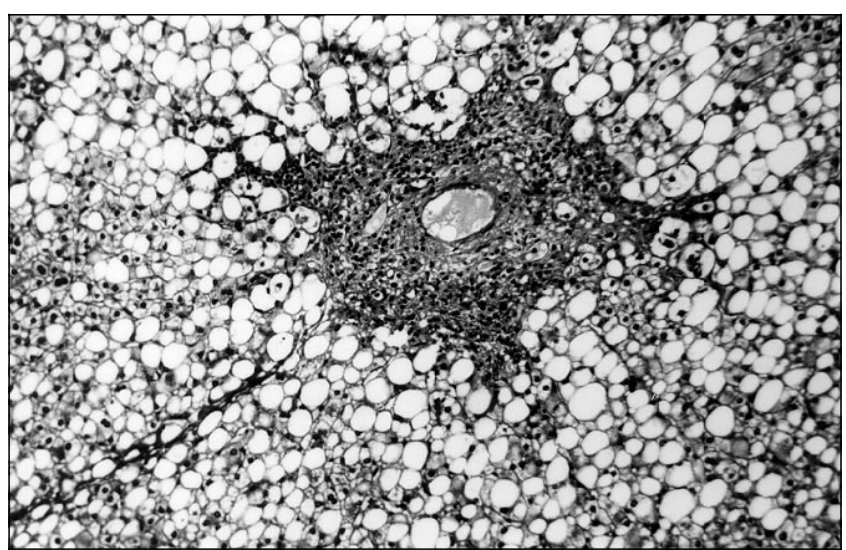

Figure 1) Grade IIIA liver biopsy showing periportal fibrosis in a background of marked steatosis (hematoxylin and eosin x246)

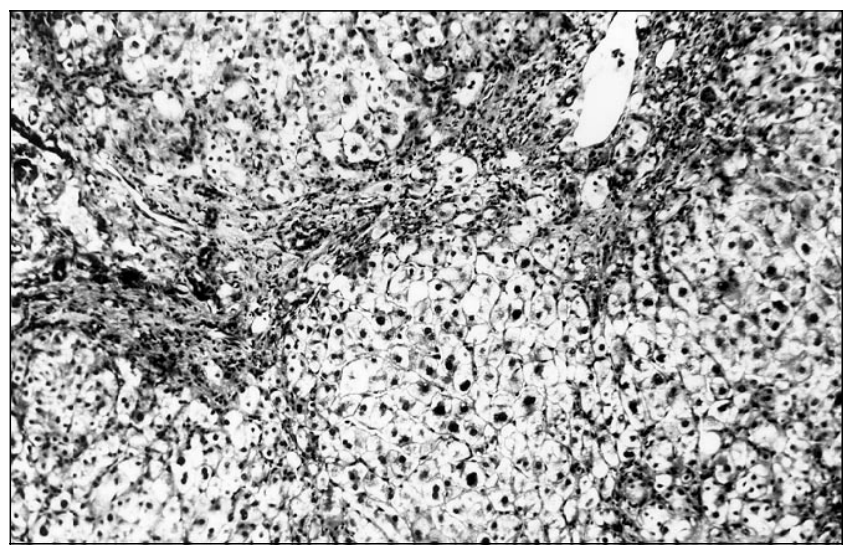

Figure 2) Grade IIIB liver biopsy showing periportal and bridging fibrosis, the latter linking two adjacent portals (hematoxylin and eosin x246)

The biopsies were designated grades according to the system proposed by Roenigk et al (11) in 1982: grade I indicates normal or mild steatosis, mild nuclear variability, mild portal inflammation; grade II, presence of moderate to severe steatosis, portal expansion by fibrosis with or without inflammation; grade IIIA, presence of periportal fibrosis (Figure 1); grade IIIB, presence of bridging fibrosis linking adjacent portal areas (Figure 2); and grade IV, the presence of cirrhosis (Figure 3).

Patient data: The inclusion criteria for this study were patients with psoriasis who had a pre-MTX liver biopsy and who had regular annual follow-up biopsies while on MTX. All patients included in the study were screened for risk factors before MTX was instituted and were followed up clinically, with routine blood and biochemical screening while on MTX. Excluded were patients with psoriasis receiving MTX for less than one year and those on MTX for whom baseline or regular annual follow-up biopsies were not available for histological evaluation.

Clinical data were extracted from medical records and compared with the histological grades. The following clinical data were documented: sex, age at start of therapy, indi-

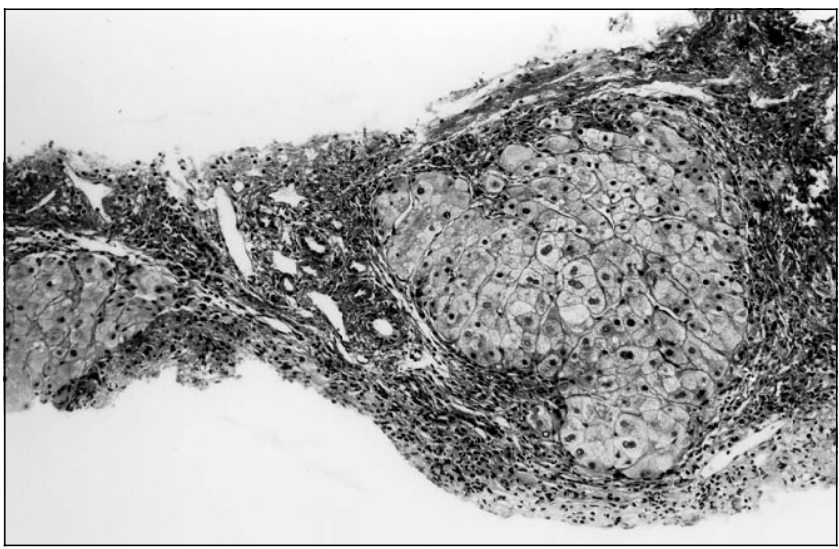

Figure 3) Grade IV liver biopsy showing cirrhosis manifested by a complete and part of another (far left) regenerative nodules surrounded by fibrosis (hematoxylin and eosin X246)

\section{TABLE 1 \\ Age and sex distribution of 104 psoriatic patients on methotrexate}

\begin{tabular}{lccc}
\hline Age group (years) & Female & Male & Both \\
\hline $10-19$ & 3 & 1 & 4 \\
$20-29$ & 2 & 13 & 15 \\
$30-39$ & 11 & 20 & 31 \\
$40-49$ & 13 & 11 & 24 \\
$50-59$ & 5 & 3 & 8 \\
$60-69$ & 9 & 10 & 19 \\
Over 70 & 2 & 1 & 3 \\
Total & 45 & 59 & 104 \\
Age range & $16-71$ & $18-70$ & $16-71$ \\
Mean age & 45.6 & 40.7 & 42.8 \\
\hline
\end{tabular}

cations, dosage and mode of administration of MTX, cumulative dose of MTX before each follow-up biopsy, body height and weight, clinical diagnosis of obesity, presence of diabetes mellitus and alcohol ingestion.

MTX was given in 5 to $25 \mathrm{mg}$ weekly doses either as a single dose or as one-third of the dose every $12 \mathrm{~h}$ once per week. The estimated annual dose ranged from 1 to $1.5 \mathrm{~g} /$ patient.

According to the guidelines, MTX was discontinued in all patients with histological grades IIIB or IV. Patients with grade IIIA liver biopsies continued to receive MTX but were monitored with regular liver biopsies either annually, when the periportal fibrosis was mild, or at six- to nine-month intervals, when there was evidence of impending grade IIIB change.

Statistics: Differences in years of follow-up between sex groups and between the alcohol, obesity and diabetes risk factor groups were assessed by the Wilcoxon rank sum test. Differences in follow-up between initial biopsy grade, final biopsy grade and age were assessed by Spearman's correlation coefficient. Differences in initial biopsy grade between males and females, and among the diabetes, obesity and alcohol risk 
TABLE 2

Years of follow-up while on methotrexate therapy

\begin{tabular}{lccc}
\hline Years & Females & Males & Total \\
\hline 1 & 7 & 12 & 19 \\
2 & 12 & 15 & 27 \\
3 & 9 & 7 & 16 \\
4 & 7 & 3 & 10 \\
5 & 3 & 3 & 6 \\
6 & 2 & 6 & 8 \\
7 & 1 & 2 & 3 \\
8 & 0 & 4 & 4 \\
9 & 3 & 3 & 6 \\
10 & 1 & 2 & 3 \\
11 & 0 & 2 & 2 \\
Mean & 3.5 & 4.1 & 3.81 \\
\hline
\end{tabular}

TABLE 3

Patients with risk factors: obesity, diabetes and alcohol consumption*

\begin{tabular}{lccc}
\hline Risk factor & Females & Males & Total \\
\hline Obesity & 7 & 7 & 14 \\
Diabetes & 2 & 0 & 2 \\
Alcohol consumption & 4 & 16 & 20 \\
Obesity + diabetes & 5 & 0 & 5 \\
Obesity + alcohol consumption & 7 & 7 & 14 \\
Diabetes + alcohol consumption & 1 & 0 & 1 \\
Obesity + diabetes + alcohol & 1 & 1 & 2 \\
$\quad$ consumption & & & \\
\hline
\end{tabular}

${ }^{*}$ No greater than three drinks per week (a drink constitutes $30 \mathrm{~mL}$ of hard liquor, $118 \mathrm{~mL}$ of wine or $355 \mathrm{~mL}$ of beer)

factor groups were assessed by the Wilcoxon rank sum test. Differences in initial biopsy grade by age were assessed by Spearman's correlation coefficient.

Odds ratios for the risk of liver biopsy grade progression, and for the risk of progression to grades IIIB and IV, for obesity, diabetes and alcohol risk factors were estimated by logistic regression (17). Age and years of follow-up were initially used as covariates and found to be nonsignificant. Therefore, they were omitted from the model producing the final estimates.

All analyses were done using SAS statistical software (SAS Institute, North Carolina).

\section{RESULTS}

A total of 104 patients fulfilled the inclusion criteria (Table 1). There were 45 females, mean age 44.2 years (range 16 to 71 ), and 59 males, mean age 39.2 years (range 18 to 70 ).

Mean follow-up was 3.5 years for female patients, 4.1 years for males and averaged 3.8 years for all patients (range one to 11) (Table 2). There were no statistical differences in followup by sex $(\mathrm{P}=0.67)$, age (comparing younger than 40 years with older than 40 years) $(\mathrm{P}=0.28)$, alcohol consumption status $(\mathrm{P}=0.92)$, obesity status $(\mathrm{P}=0.80)$, diabetes status $(\mathrm{P}=0.95)$, or initial liver biopsy grade $(\mathrm{P}=0.08)$.

Thirty-five patients, 20 females and 15 males, were identified as obese. Obesity was at least 20\% above normal body mass index in 28 patients (72\%). Obesity was determined from body weight combined with clinical statement of 'obese' in seven patients (18\%) and from clinical statement alone in four $(10 \%)$. Ten patients, nine females and one male, had biochemically determined diabetes mellitus ( $\mathrm{Ta}$ ble 3).

All patients had been advised against drinking alcoholic beverages before MTX administration. Thirty-seven patients, 13 females and 24 males, admitted to social or occasional alcohol consumption, which was defined as no greater than three drinks per week (a drink constituted $30 \mathrm{~mL}$ of hard liquor, $118 \mathrm{~mL}$ of wine or $355 \mathrm{~mL}$ of beer) (personal communication)

There were 477 biopsies, 104 baseline biopsies (pre-MTX treatment) and 373 annual follow-up biopsies. The histological grading of the liver biopsies is shown in Figure 4. Eighty patients started with baseline grade I liver biopsies, 16 with grade II liver biopsies and eight (five females and three males) with grade IIIA biopsies. None of the biopsies showed evidence of alcoholic hepatitis, chronic viral hepatitis or
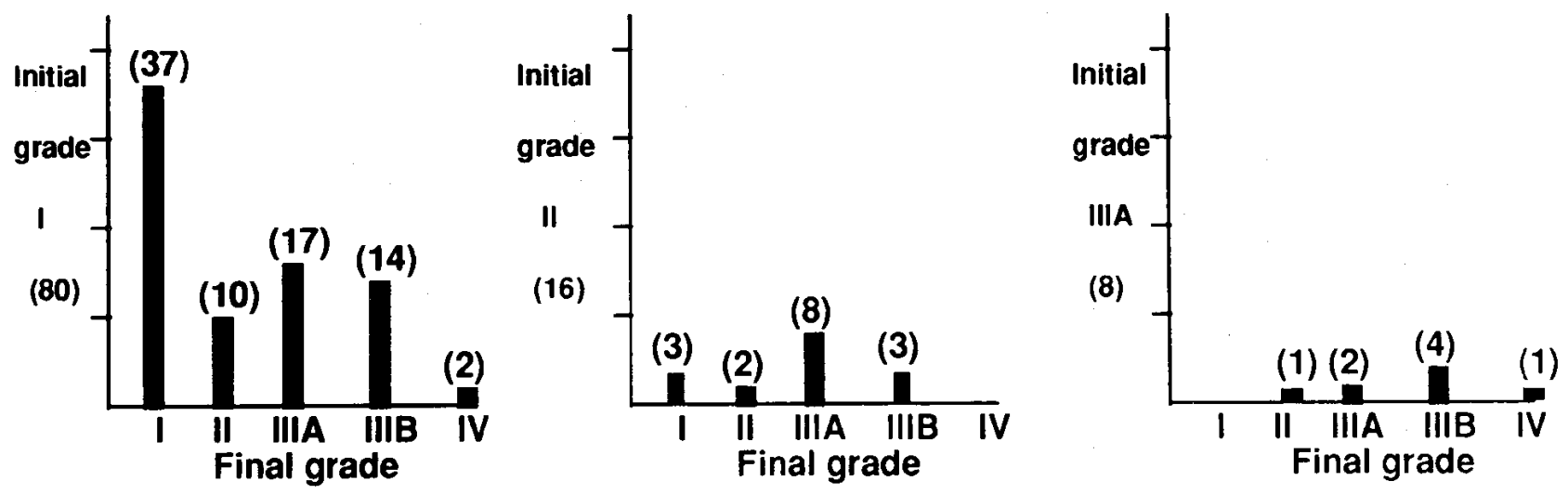

Figure 4) Progression of liver biopsy initial grades. Numbers inside brackets refer to the number of patients 
increased accumulation of stainable iron. There were no statistically significant differences in the initial biopsy grade by sex $(\mathrm{P}=0.67)$ or alcohol use status $(\mathrm{P}=0.82)$. However, the obese group $(\mathrm{P}=0.006)$ and the diabetes group $(\mathrm{P}=0.004)$ had a higher percentage of grades II and IIIA biopsies, and initial biopsy grade was positively correlated with age $(\mathrm{P}=0.003)$.

Figure 4 also shows the progression of the initial grades at the end of the study. Of the 80 patients with grade I baseline biopsies, 37 continued with the same grade, 10 patients developed grade II changes, 17 developed grade IIIA changes, 14 developed grade IIIB changes and two developed cirrhosis. Eight of the 16 patients with grade II baseline biopsies developed grade IIIA changes and three developed grade IIIB changes. Four patients in the grade IIIA baseline group developed grade IIIB changes and one developed cirrhosis. The retrograde change from a higher to a lower grade seen in three patients with baseline grade II and one patient with initial grade IIIA is attributed to biopsy sampling variation. Increased biopsy grade progression was associated with obesity $(\mathrm{P}=0.001)$, but not with alcohol $(\mathrm{P}=0.93)$ and diabetes $(\mathrm{P}=0.42)$ (Table 4$)$.

At the end of the study 40 patients had grade I liver biopsies, 13 had grade II liver biopsies, 27 had grade IIIA liver biopsies, 21 had grade IIIB liver biopsies and three (two females and one male) had final grade IV liver biopsies. Progression to final grades IIIB and IV was associated with diabetes $(\mathrm{P}=0.02)$ but not with obesity or alcohol use (Table 4).

The three patients who developed cirrhosis did so within two years of MTX therapy (Table 5). These were one male and two females, age 22, 42 and 66 years, respectively. The pre-MTX biopsies were grade I in two patients and grade IIIA in one. All three were obese and only one admitted to occasional alcohol consumption.

The three patients who had MTX stopped because of grade IIIB liver biopsy after three to six years (average 4.3) of treatment are described in Table 6. After two to three years of withdrawal from MTX, the liver histology improved to grades I, II and IIIA. However, the liver grades reverted back to IIIB after one to two years (average 1.3) of MTX resumption.

\section{DISCUSSION}

Hepatic fibrosis and cirrhosis are the most serious side effects of MTX therapy for psoriasis. Routine monitoring of liver function tests does not reflect the slow progressive underlying fibrosis with minimal inflammation due to MTX. On the other hand, several studies have shown that histological examination of liver biopsies is the most accurate available means of monitoring MTX-induced hepatotoxicity and minimizing the risk of cirrhosis $(4,18-22)$. Nevertheless controversy exists on the justification for liver biopsies before treatment with MTX. This issue is especially debated when applied to patients with rheumatoid arthritis because it has been shown that such patients are at a lower risk of developing serious MTX-related hepatotoxicity $(14,23,24)$. As a result of this controversy, the latest guidelines (12) recom-
TABLE 4

Effect of diabetes, obesity and alcohol on disease progression and final grade of liver biopsies

\begin{tabular}{|c|c|c|c|}
\hline Risk factor & Odds ratio & $95 \% \mathrm{Cl}$ & $\mathbf{P}$ \\
\hline \multicolumn{4}{|c|}{ Progression of liver pathology to higher grade } \\
\hline Diabetes & 2.07 & $0.35-12.35$ & 0.42 \\
\hline Obesity & 8.85 & $3.14-25.00$ & 0.001 \\
\hline Alcohol & 0.96 & $0.38-2.46$ & 0.93 \\
\hline \multicolumn{4}{|c|}{ Progression of liver pathology to grades IIIB and IV } \\
\hline Diabetes & 5.68 & $1.34-24.39$ & 0.02 \\
\hline Obesity & 2.23 & $0.82-6.06$ & 0.12 \\
\hline Alcohol & 2.23 & $0.81-6.10$ & 0.12 \\
\hline
\end{tabular}

mend that the baseline (pre-MTX therapy) biopsy be postponed in some patients for up to four months after MTX treatment initiation to assess the initial response to the drug. If long term MTX treatment is anticipated, liver biopsy is then to be taken (12). The delay in obtaining a baseline liver biopsy may be justified, particularly in patients with no clinical or biochemical suggestion of preexisting risks of liver disease. This risk includes obesity, diabetes and history of heavy alcohol consumption. All patients in this study had pre-MTX biopsies because of a consensus among the dermatologists and gastroenterologists in our institution to adhere to the recommendations proposed in the 1973 guidelines from the International Cooperative Group (10). Moreover, a number of investigators have demonstrated significant fibrosis and even cirrhosis in psoriatic patients before MTX therapy $(6,8,25)$. In this series, eight patients $(7.7 \%)$ had pre-MTX liver biopsies with IIIA changes. Because both diabetes and obesity predispose to liver fibrosis and occasionally to cirrhosis (26), assessment of a pre-MTX liver biopsy should be helpful to identify patients at a particularly increased risk for an accelerated MTX hepatotoxicity.

The small number of patients (eight) with pre-MTX grade IIIA liver biopsies in this study did not allow definitive statistical conclusions for prediction of the outcome with prolonged MTX treatment. The progression of five patients $(62.5 \%)$ in this group to bridging fibrosis and cirrhosis may suggest an increased risk with presence of a preexisting liver pathology. Other studies have shown a similar conclusion (16). On the other hand, three of the five patients who developed advanced liver fibrosis in this study were obese, one was obese and diabetic, and one had no known risk factor. We believe that pre-MTX liver biopsies, even in the absence of known risk factors, provide valuable baseline histological information that allows not only detection of subclinical liver pathology, but also assessment of the rate at which MTX-induced hepatotoxicity may evolve in a particular patient.

Our results reiterate the previously reported increased risk for MTX-induced hepatotoxicity in obese and diabetic patients. However, the risk of severe hepatic fibrosis and cirrhosis in our series is found only in diabetic patients. There is reported evidence that alcohol accentuates the hepatotoxic- 
TABLE 5

Data on three patients with accelerated evolution of cirrhosis while on methotrexate (MTX) for psoriasis

\begin{tabular}{lccccccc}
\hline & & & & & \multicolumn{3}{c}{ Risk factor } \\
Age & Sex & Initial grade & Years on MTX & Final grade & Obesity & Diabetes & Alcohol consumption \\
\hline 66 & F & IIIA & 2 & IV & Yes & No & No \\
22 & M & I & 2 & IV & Yes & No & Occasional \\
42 & F & I & 2 & IV & Yes & No & No \\
\hline
\end{tabular}

TABLE 6

Data on three patients re-exposed to methotrexate (MTX) after it was discontinued because of high grade liver biopsy

\begin{tabular}{|c|c|c|c|c|c|c|c|c|}
\hline Age & Sex & Initial grade & Years on MTX & Grade when discontinued & Abstinence & Grade at restart & Years on MTX & Final \\
\hline 31 & $\mathrm{M}$ & I & 6 & IIIB & 3 years & I & 2 & IIIB \\
\hline 41 & $\mathrm{~F}$ & II & 3 & IIIB & 2 years & IIIA & 1 & IIIB \\
\hline 45 & $\mathrm{~F}$ & I & 4 & IIIB & 2 years & ॥ & 1 & IIIB \\
\hline
\end{tabular}

ity potential of MTX $(6,7,27)$, but we did not find a statistically significant correlation with alcohol consumption in our patient population. All our patients had been warned at the outset of the adverse effect of alcohol while on MTX; the lack of statistical correlation may indicate this group of patients were generally compliant. However, 35 patients did admit to social drinking. As expected, the determining risk factor is the quantity of alcohol consumed (14). Other investigators have found that history of pretreatment alcohol consumption does not increase risk of MTX-induced hepatotoxicity (15). We believe that patients should continue to be instructed to abstain from drinking while on MTX.

Our findings of $19 \%$ of grade IIIB and 3\% of grade IV in our patients agree with those reported by the International Cooperative Group (6) and are much lower than those in the Scandinavian studies $(8,13)$. The higher Scandinavian results are thought to be due to longer years of exposure to MTX, higher cumulative doses of MTX or both.

The three patients in this series who developed cirrhosis over two years of standard MTX therapy may represent a subgroup of patients with an unusual high hepatic susceptibility to MTX. These patients underline the importance of regular follow-up liver biopsies while patients are on MTX. Zachariae and Sogaard (18) have suggested that MTXinduced cirrhosis is 'benign' compared with alcoholic cirrhosis and that MTX can cautiously be continued despite biopsy-proven cirrhosis. In contrast, Gilbert et al (19) reported three patients who required liver transplantation for MTX-induced cirrhosis. In our practice, we have followed the recommended guidelines and discontinued MTX in all patients with grades IIIB or IV and instead used alternative treatment.

Of interest are the three patients who were given MTX after it had been discontinued for two to three years because of grade IIIB liver biopsies (Table 6). These patients received alternative therapy until their interim biopsies showed improved histology not contraindicating the use of MTX. All three patients developed an accelerated progression to grade IIIB once MTX was reinstituted. This previously unreported feature raises the possibility of an acquired increased suscep- tibility to MTX. Newman and colleagues (15) have documented improvement in the histological status of the liver upon cessation of MTX but have not reported an accelerated hepatotoxicity upon resumption of MTX. In their experience, some patients did not develop fibrosis or cirrhosis upon resumption of MTX. They do recommend, however, followup liver biopsy at shorter intervals in these patients.

This study was completed before laboratory diagnosis of hepatitis $\mathrm{C}$ virus (HCV) became available, and because a number of nonspecific histological features of chronic $\mathrm{HCV}$ infection and MTX hepatotoxicity (such as portal infiltrate, steatosis and fibrosis) overlap, it may be argued that some of the pre-MTX grade IIIA liver biopsies are related to HCV. The absence of more characteristic histological features, ie, hepatocellular necrosis, sinusoidal lymphocytosis and portal lymphoid follicles, makes the possibility of chronic HCV infection less likely, however.

\section{CONCLUSIONS}

We report the first Canadian study on MTX-induced liver injury in patients with psoriasis. Despite close follow-up protocol and adherence to strict guidelines, this study reiterates the strong hepatotoxic potential of MTX in patients with psoriasis, and the increased risk in patients who are obese and diabetic. An unusual finding in our study is the unpredictable rapid histological deterioration of three patients' liver biopsies linked with obesity, pre-existing mild hepatic fibrosis and re-exposure to MTX after MTX was discontinued because of high grade fibrosis.

\section{REFERENCES}

1. Roenigk HH Jr, Haserick JR, Curtis GH. Methotrexate for psoriasis. Cleve Clin Q 1963;3:211-5.

2. Hanno R, Gruber GG, Owen LG, Callen JP. Methotrexate in psoriasis: a brief review of indications, usage, and complications of methotrexate therapy. J Am Acad Dermatol 1980;2:171-4.

3. Roenigk HH Jr, Haserick JR, Curtis GH. Methotrexate for psoriasis. Cleve Clin J Med 1983;50:101-5.

4. Weinstein GD. Commentary: three decades of folic acid antagonists in dermatology. Arch Dermatol 1983;119:525-7.

5. Edmundson G, Guy W. Treatment of psoriasis with folic acid antagonist. Arch Dermatol 1958;78:200-3. 
6. Weinstein G, Roenigk HH, Maibach H, Cosmides J, Halprin K, Millard M. Psoriasis-liver-methotrexate interactions. Arch Dermatol 1973;103:35-42.

7. Ashton RE, Millward-Sadler GH, White JE. Complications in methotrexate treatment of psoriasis with particular reference to liver fibrosis. J Invest Dermatol 1982;79:229-32.

8. Zachariae H, Kragballe K, Sogaard H. Methotrexate induced liver cirrhosis: studies including serial liver biopsies during continued treatment. Br J Dermatol 1980;102:407-12.

9. Roenigk HH Jr, Maibach HI, Weinstein G. Guidelines on methotrexate therapy for psoriasis. Arch Dermatol 1972;105:363-5.

10. Roenigk HH Jr, Maibach HI, Weinstein G. Methotrexate therapy for psoriasis: guidelines revisions. Arch Dermatol 1973;108:36-42.

11. Roenigk HH Jr, Auerbach R, Maibach HI, Weinstein G. Methotrexate guidelines: revised. J Am Acad Dermatol 1982;6:145-55.

12. Roenigk HH Jr, Auerbach R, Maibach HI, Weinstein G. Methotrexate in psoriasis: revised guidelines. J Am Acad Dermatol 1988;19:145-56.

13. Nyfors A. Liver biopsies from psoriatics related to methotrexate therapy. Acta Pathol Microbiol Immunol Scand 1977;85:511-8.

14. O'Keefe QEW, Fye KH, Sack KD. Methotrexate and histologic hepatic abnormalities: a meta-analysis. Am J Med 1991;90:711-6.

15. Newman M, Auerbach R, Feiner H, et al. The role of liver biopsies in psoriatic patients receiving long-term methotrexate treatment. Arch Dermatol 1989;125:1218-24.

16. O'Connor GT, Olmstead EM, Zug K, et al. Detection of hepatotoxicity associated with methotrexate therapy for psoriasis. Arch Dermatol 1989;125:1209-17.
17. Agresti A. Categorical Data Analysis. New York: John Wiley and Sons, 1990:84-91.

18. Zachariae H, Sogaard H. Methotrexate induced liver cirrhosis: a follow-up. Dermatologica 1987;175:178-82.

19. Gilbert SC, Klintmalm G, Mentor A, Silverman A. Methotrexateinduced cirrhosis requiring liver transplantation in three patients with psoriasis. A word of caution in light of the expanding use of this "steroid-sparing" agent. Arch Intern Med 1990;150:889-91.

20. Reese LT, Grisham JW, Aach RD, Eisen AZ. Effect of methotrexate on the liver in psoriasis. J Invest Dermatol 1974;62:597-602.

21. Zachariae H, Grunnet E, Sogaard H. Liver biopsy in methotrexatetreated psoriasis - a re-evaluation. Acta Derm Venereol (Stockh) 1975;55:291-6.

22. Van de Kerhof PCM, Hoefnagels WHL, Van Haelst UJGM, Mali JWH. Methotrexate maintenance therapy and liver damage in psoriasis. Clin Exp Dermatol 1985;10:194-200.

23. Health and Public Policy Committee, American Collage of Physicians. Position Paper: methotrexate in rheumatoid arthritis. Ann Intern Med 1987;107:418-9.

24. Kremer JM, Koff R. A debate: Should patients with rheumatoid arthritis on methotrexate undergo liver biopsies? Semin Arthritis Rheum 1992;21:376-86.

25. Nyfros A, Poulsen H. Liver biopsies from psoriatics related to methotrexate therapy. Acta Pathol Microbiol Immunol Scand 1976;84:262-70.

26. Alder M, Schaffner F. Fatty liver hepatitis and cirrhosis in obese patients. Am J Med 1979;67:811-6.

27. Tobias H, Auerbach R. Hepatotoxicity of long-term methotrexate therapy for psoriasis. Arch Intern Med 1973;132:391-6. 


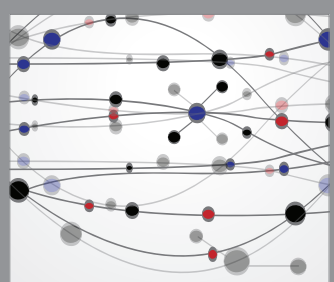

The Scientific World Journal
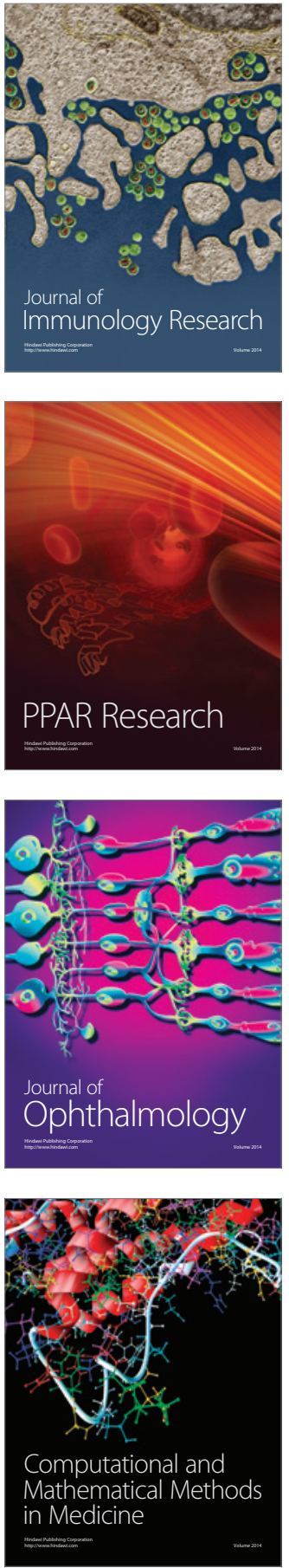

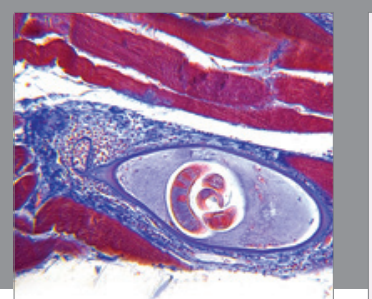

Gastroenterology Research and Practice

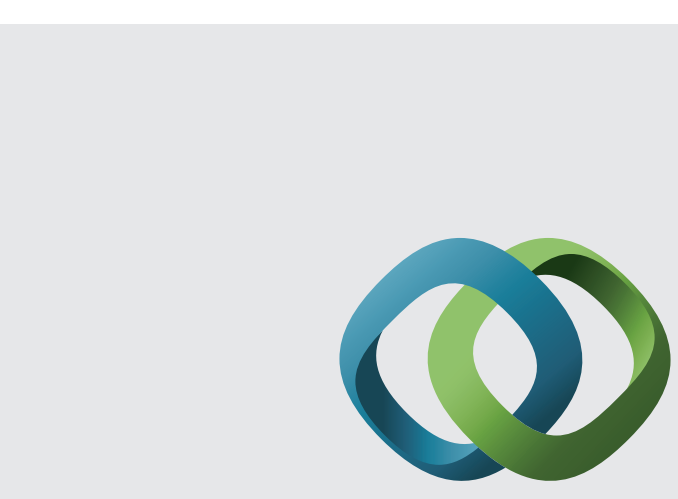

\section{Hindawi}

Submit your manuscripts at

http://www.hindawi.com
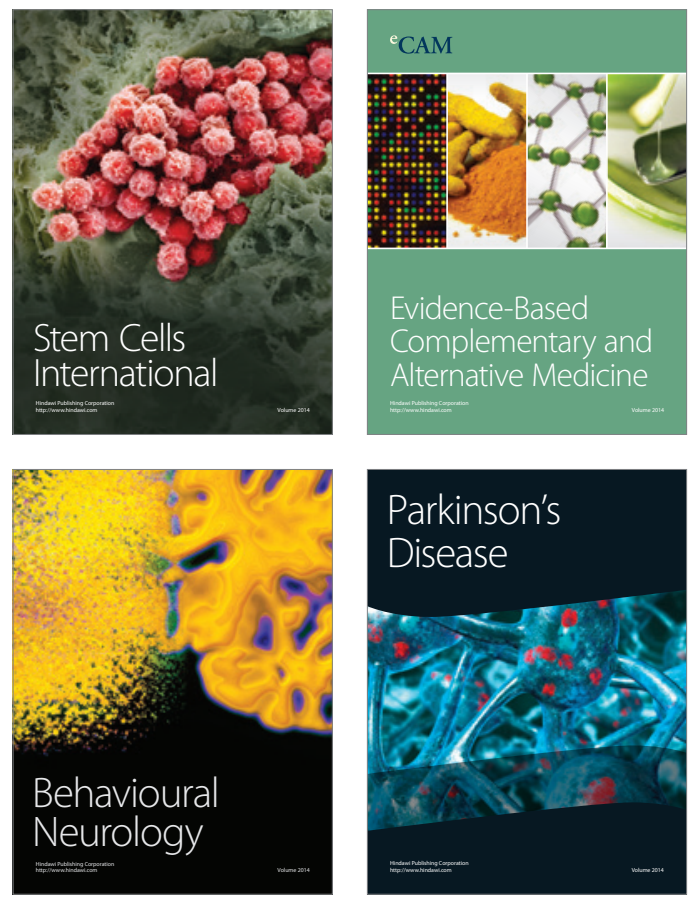
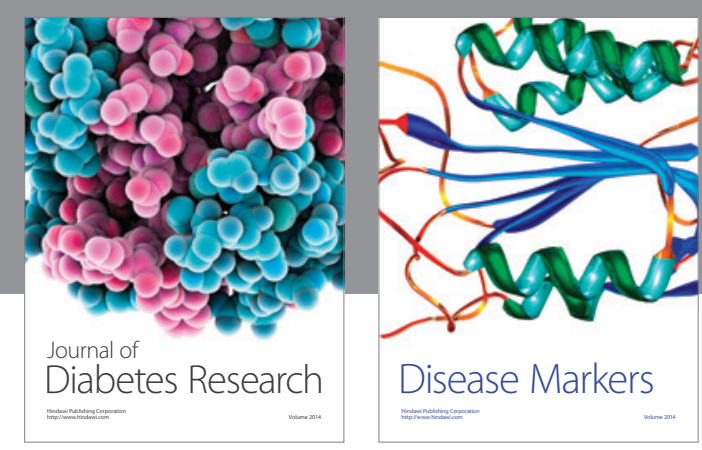

Disease Markers
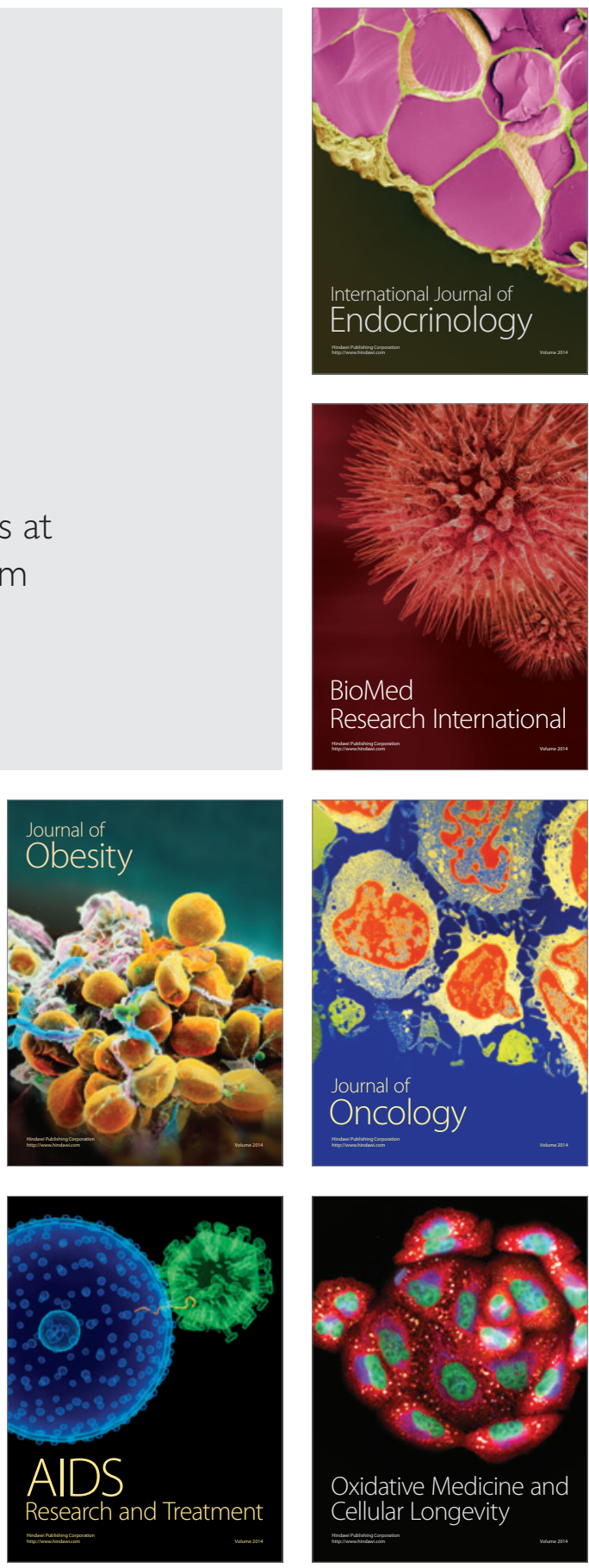